\title{
Study on Strategies of Construction of Characteristic Towns with Sports Specialty in Qinling Mountains in Xi'an District
}

\author{
Nan Zhang ${ }^{1, a,}{ }^{*}$, Chaoyang Gao ${ }^{1}$ and Manhua $\mathrm{Li}^{1}$ \\ ${ }^{1}$ Sport Institute, Xi'an University of Technology, Xi'an, China \\ abluenan1@126.com \\ ${ }^{*}$ Corresponding author
}

Keywords: Xi'an district, Qinling Mountains, sports specialty, town, development strategy specialty

\begin{abstract}
This paper analyzes the advantage of resources in constructing characteristic towns with sports specialty in Xi'an Qinling Mountainous areas. According to both the theory of constructing characteristic towns with sports specialty and experience of it from home and abroad, this paper also proposes the strategies of constructing characteristic town with sports specialty as follows: 1 . take advantage of local resources to plan and design the development of the town accurately; 2. highlight the specialty of each town and value the individual experience of tourists; 3 . innovate the operating model and attract the investment of private capital; 4. give priority to environmental conservation and build the overall ecological pattern.
\end{abstract}

\section{西安秦岭体育特色小镇建设的策略研究 \\ 张楠 ${ }^{1}, \mathrm{a},{ }^{*}$ ，高朝阳 ${ }^{1} ，$ 李曼华 ${ }^{1}$ \\ 1西安理工大学体育部, 西安, 陕西, 中国 \\ abluenan1@126.com \\ 通讯作者}

关键词：西安；秦岭；体育特色；小镇；发展策略

中文摘要. 分析了西安秦岭体育特色小镇建设的资源优势, 根据体育小镇建设的相关理论, 结合国内外体育特色小镇建设经验, 提出了西安秦岭发展体育特色小镇的策略: 1. 发挥资源 优势, 精确定位, 做好规划; 2. 突出小镇特色, 注重游客体验感受; 3. 创新运作模式, 推动 民间资本进入；4．坚持保护优先，注重整体生态格局的营造。

\section{1. 引言}

体育特色小镇是当地利用自身资源优势，以发展体育旅游业为导向，通过建设运动项目 基地、体育休闲设施、举办体育赛事等吸引游客形成可观赏和亲身参与各种体育活动的行为, 进而发展为观赏型体育旅游和参与性体育旅游, 从而形成拥有完备体育产业链条以及较好生 态环境的宜居特色小镇。

中国体育特色小镇建设才刚刚起步。2016年7月，住房城乡建设部、国家发展改革委、财 政部联合发出《关于开展特色小城镇培育工作的通知》, 到 2020 年争取培育 1000 个左右各具 特色、富有活力的特色小镇。10月，国务院办公厅出台了《关于加快发展健身休闲产业的指 
导意见》, 提出结合新型城镇化建设等国家重大部署, 以健身休闲重点运动项目和产业示范 基地等为依托, 鼓励地方积极培育一批以健身休闲为特色的服务贸易示范区。同年, 国家旅 游局与国家体育总局签署了《关于推进体育旅游融合发展的合作协议》等，旅游牵手体育拉 动地区经济发展成为必然趋势, “体育旅游” 将开创全民健身的新时尚。相关政策的密集出 台, 使得体育产业受到前所未有的高度重视。体育产业是经济转型升级的推手, 也是促进消 费的增长点。体育特色小镇是发展体育产业的重要载体之一, 越来越多的地方表现出孵化新 体育特色小镇的意愿。从传统观赏型旅游向体验式旅游转变、将体育产业开发和新型城镇化 建设相互融合的体育小镇建设将迎来井喷式发展。

\section{2. 国内外体育特色小镇的发展状况}

\section{1 国外体育特色小镇的发展状况}

国外发展成熟的体育小镇不仅具有优越的人居环境，深厚的历史文化遗迹和特色鲜明的 城市风貌, 而且很多还是著名大学、世界著名企业的总部所在地, 集中了很多大城市也无法 比拟的资源优势。如全球体育用品公司总部所在地一一德国赫尔佐根赫若拉赫，是三家全球 企业阿迪达斯、彪马、舍弗勒的总部, 他们为当地经济带来 1.67 万个就业岗位（2011 年）。 作为全球体育用品商的阿迪达斯是城市区域里最大的公司, 每年营业额为 145 亿欧元, 在全 球共拥有 4.7 万名雇员; 还有众多瑞士滑雪小镇如达沃斯, 它不仅是世界经济论坛的举办地, 还是 “欧洲最大的高山滑雪场” 。达沃斯小镇位于瑞士东南部格里松斯地区, 靠近奥地利边 境, 是阿尔卑斯山系海拔最高的小镇。瑞士经典火车路线 “冰河列车” 在这里有必经的一站。 达沃斯是欧洲人心中的 “人间天堂”，是欧洲大型的顶级滑雪胜地之一。在滑雪旺季，超过 70 万游客来这里度假。

\section{2 中国体育特色小镇的发展现状}

中国体育小镇建设才刚刚起步。在特色小镇建设上走在全国前列的浙江省、江苏省等地, 健身休闲类的体育特色小镇已经在各地涌现。以浙江德清莫干山 “裸心” 体育小镇为例, 目 前, 在德清有体育产业企业70多家，均以体育健身休闲、场馆服务及体育用品的销售和制造 为主，2014年实现体育产业销售收入过百亿元，体育产业项目计划投资额达 12.6 亿元。浙江 省政府还专门出台了《关于加快发展体育产业促进体育消费的若干意见》, 该意见指出, 将 建设环杭州湾、环舟山群岛、环太湖和环浙南等运动休闲发展带, 培育创建一批体育特征突 出、产业基础较好、产业融合潜力较大的特色小镇。在 2016 江苏体育产业大会上, 江苏省体 育局与首批 8 个体育健康特色小镇所在县 (市、区) 政府签署了共建协议, 以省地共建模式在 全国率先启动体育健康特色小镇建设。

\section{3. 体育特色小镇的相关概念}

\section{1 建设体育特色小镇的意义}

体育特色小镇建设具有独一无二的内涵: 体育特色小镇是融合体育项目相关产业、当地文 化、旅游、社区功能的创新创业发展平台。“体育特色小镇” 建设本质上是对特定空间内各 类生产要素、制度要素、文化要素的重新整合和高效利用, 尤其在中国经济步入调整期、国 家加大改革开放力度以及体育产业政策的情况下 “体育小镇” 以其对政府公共服务、体育产 业资本及社会元素的全新组合, 激发出当地社会经济发展的新型驱动力, 是 “供给侧” 有效 的改革手段。同时体育特色小镇建设理念与新时期都市人的生活方式不谋而合。随着大城市 中居民对不同生活方式的追求, 郊区化和小城镇化不可阻挡, 逃离城市拥堵、喧闹以及近几 年困扰大城市的城市雾霾是每个都市人心中的梦想。而生态环境优美的体育特色小镇建设聚 
焦的 “信息、环保、健康、体育旅游、时尚、和休闲” 等产业, 将吸引大量的都市人成为主 流消费人群，可以预见两者未来在实践上的互动、共享将是新常态。

\section{2 体育特色小镇的分类}

体育特色小镇的探索和开发，可以根据当地体育产业与其他产业的整合尤其是与旅游业 的结合、就业人口及休闲化消费的聚集、城镇基础配套设施及服务为依据, 其开发模式可分 为如下几类:

赛事型体育特色小镇。结合地理区位场地特征或地方体育产业特色，打造以单项体育活 动项目为核心的产业集群或产业生态链的体育类特色小镇。此类型小镇对场地条件有特殊要 求, 标准较高, 但是可以通过单项体育活动打造影响力, 经常性的承办大型赛事活动, 有较 强的观赏性价值，同时赛后，利用场地发展相关的体育活动。

休闲型体育特色小镇。依托距离较近的旅游景区, 结合场地资源, 以户外体育运动和体 验项目为主, 打造体育产业全民化、多元化、娱乐体验式的发展路径, 依托体育赛事及休闲 体验活动走体育产业与旅游相结合的发展道路, 建设具有较强参与性的体育类休闲特色小镇。

度假型体育小镇。依托较近自然环境独具特色旅游区优美的自然环境, 打造的以高端度 假类体育活动 (如高尔夫、滑雪、房车露营等) 为主、体验性较强的体育产业, 并结合旅游、 健康、养生发展成为体育度假旅游型特色小镇。

产业型体育特色小镇。依托体育生产制造产业, 发展新型智慧体育活动、休闲娱乐等体 验活动, 延伸发展体育文化、体育博览进而形成体育产业上下游产业链, 并与健康、旅游相 结合发展为体育产业型特色小镇。一般集中于新城区建设, 实现智慧体育新区发展。

\section{4. 西安秦岭体育特色小镇的发展策略}

秦岭是国际化大都市西安的后花园、是旅游避暑胜地之一，其文化资源和自然资源充沛， 高山湖泊、河流、草甸、湿地、森林、雪山等构成了秦岭的多层次、丰富多样的大地生态景 观, 为游客提供了最为淳朴、自然、绿色的体育运动体验和参与方式, 有别于都市健身的喧 器, 这都得益于秦岭山区独一无二的自然资源。目前, 西安秦岭地区的山地体育产业已初具 规模, 如以秦岭山地越野挑战赛, 秦岭山地自行车比赛为代表的体育竞赛表演业, 以翠华山 高山滑雪、秦岭高尔夫球场为代表的体育场馆业已受到了社会各界的好评与认可, 2017年春 节期间就有 1.3 万名游客到秦岭翠华山滑雪场滑雪。但该地区提供体育服务与用品的企业仍处 于分散经营, 空间集聚不合理; 缺乏统一规划, 各业态的组合分布没有规则; 区域体育产业 资源整合不够, 基础设施建设滞后; 造成如此局面的根本原因在于西安秦岭还未形成独立的 平台来聚合相关产业, 不能突出秦岭山地体育产业的特色。西安秦岭体育特色小镇建设将全 面结合秦岭实际, 以秦岭山地体育休闲产品为特色, 以旅游景区为核心打造一条体育活动与 旅游的全产业链, 开展以政府主导、全民参与、市场运作为主导方式的秦岭体育休闲旅游创 新平台。

\section{1 发挥资源优势, 精确定位, 做好科学规划}

特色镇建设，规划是龙头、是先导，在小镇建设之初就要考虑 “概念策划、空间规划、 项目计划和资金筹划” 等 “四划叠加” 的综合性方案, 并积极向国际流行的 “多规融合” 靠 拢, 同时小镇建设要更多的考虑如何汇聚凝炼当地人文, 更好的融体育旅游项目特色于小镇 规划中, 这不仅影响其未来的营运和向周边辐射, 更影响其小镇品牌的创建。可以在西安秦 岭地区先选择一处体育小镇进行建设, 获得示范效应后再进行推广, 如在秦岭翠华山下建设 度假型体育小镇。翠华山是国家地质公园, 拥有碧山湖景区、天池景区和山崩石海景区, 还 拥有陕西面积最大的高山滑雪场。翠华山下的太乙镇可以发展冰雪产业, 并结合旅游、健康、 养生发展成为体育度假旅游型特色小镇。 


\section{2 突出小镇特色, 注重游客体验感受}

对于以体育旅游业为主导产业的体育小镇来说, 体育特色就是吸引力、生命力和竞争力。 体育小镇的建设应根据秦岭独特的自然、文化优势，提炼出小镇的独有的体育特色。同时， 在体育小镇的建设中, 围绕小镇的体育休闲特色, 坚持继承与创新创意相结合, 在对秦岭自 然景观、历史文物古迹、体育项目的特色文化深度挖掘和利用中, 注重游客体验环境的建设, 营造游客休闲娱乐的轻松氛围, 达到吸引游客的目的, 延长游客的游览时间以及提高游客的 重游率。

\section{3 创新运作模式}

坚持 “政府引导、企业主体、市场运作” ，加强政府引导和服务保障，在规划编制、基 础设施配套、资源要素保障、文化内涵挖掘传承、生态环境保护等方面更好的发挥作用。同 时, 充分发挥市场在资源配置中的决定性作用, 凸显企业主体地位, 以企业为主推进项目建 设。鼓励支持组建融资公司，着力推动民间资本进入，全面解决项目建设资金难题。

\section{4 坚持保护优先，注重整体生态格局的营造}

体育小镇的吸引力不仅来自体育休闲项目本身, 其所在地深厚的历史文化底蕴和独特的 乡村生活风貌, 更是游客来此健身的理由, 这也是其发展的凭借和依托。在小镇开发中必须 坚持保护优先、可持续发展, 保护体育小镇赖以生存的特色体育旅游资源及良好的生态环境。 众多体育旅游小镇都有着十分突出的自然生态环境资源, 但自然生态往往是脆弱而难以恢复 的, 如果无视自然生态环境的承载力, 粗犷、无序地进行开发, 将给生态环境带来巨大冲击。 随着社会的发展, 人们认识的提高, 人与自然的和谐共处已成共识, 注重整体生态格局的营 造策略, 强调科学地、适度地利用自然生态资源, 采取主动的生态保护与建设措施, 以 “营 造” 带动 “保护” , 积极打造适应地区生态循环和演替过程的生态格局, 增强生态系统自身 稳定性，提高其生态服务能力。

\section{致谢}

本文受陕西省教育厅科研计划项目资助 (项目编号：16JK1533), 是《西安秦岭山地体育 休闲活动发展路径研究》的阶段性成果之一。

\section{References}

[1] Zhang Jian-zhong, On the Construction of Tourism Characteristic Culture Town Based on the Perspective of Scientific and Technological Innovation, Journal of Jinzhong University, vol.33, pp. 33-37, 2016.

[2] Jia Wen-yue, Historic Town Tourism Plan in The Sustainable View, Planners, vol.29, pp. 147-152, 2013.

[3] LI Xue, Study on the Feasibility of Building National Trails System in Shaanxi Qinling Mountains, Sichuan Sports Science. vol.34, pp. 106-114, 2014.

[4] Qian Qiao-xian, Research on Sports Ecology Construction of Characteristic Town, Zhejing Sport Science, vol.45, pp. 25-27, 2016.

[5] CAI Tian-shu. Local Community Participation in Urban Tourism Development: A Case Study Based on Nanjing Tangshan Hot Springs Tourist Town, Urban Development Studies, vol.22, pp. 71-80, 2015.

[6] Min Xue-qin, Characteristic Towns and Their Building Path From the Perspective of Accurate Governance, Tongji University Journal Social Science Section, vol.27, pp. 55-60, 2016. 